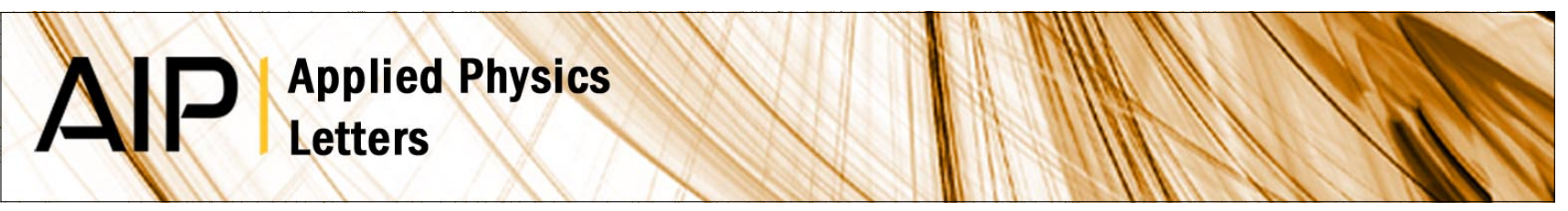

\title{
Third order nonlinear susceptibility of InN at near band-gap wavelengths
}

F. B. Naranjo, M. González-Herráez, H. Fernández, J. Solis, and E. Monroy

Citation: Appl. Phys. Lett. 90, 091903 (2007); doi: 10.1063/1.2709891

View online: http://dx.doi.org/10.1063/1.2709891

View Table of Contents: http://apl.aip.org/resource/1/APPLAB/v90/i9

Published by the American Institute of Physics.

\section{Related Articles}

Understanding of nonlinear optical properties of CS2 from a microscopic viewpoint J. Chem. Phys. 137, 084315 (2012)

Demonstration of nonlinear magnetoelectric coupling in metamaterials

Appl. Phys. Lett. 101, 051103 (2012)

Pure nonlinear optical activity in metamaterials

Appl. Phys. Lett. 101, 041911 (2012)

Light amplification in zero-index metamaterial with gain inserts

Appl. Phys. Lett. 101, 031907 (2012)

Taming the thermal emissivity of metals: A metamaterial approach

Appl. Phys. Lett. 100, 201109 (2012)

\section{Additional information on Appl. Phys. Lett.}

\section{Journal Homepage: http://apl.aip.org/}

Journal Information: http://apl.aip.org/about/about_the_journal

Top downloads: http://apl.aip.org/features/most_downloaded

Information for Authors: http://apl.aip.org/authors

\section{ADVERTISEMENT}

\section{AIP Applied Physics Letters}

\section{EXPLORE WHAT'S NEW IN APL}

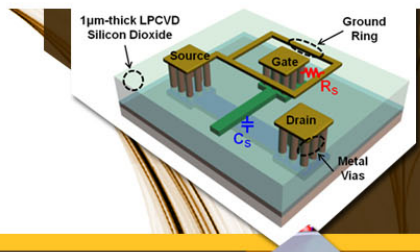

SURFACES AND INTERFACES

Focusing on physical, chemical, biological structural, optical, magnetic and electrical properties of surfaces and interfaces, and more.. 


\title{
Third order nonlinear susceptibility of $\operatorname{InN}$ at near band-gap wavelengths
}

\author{
F. B. Naranjo a) and M. González-Herráez \\ Departamento de Electrónica, Escuela Politécnica, Universidad de Alcalá, Campus Universitario, \\ 28871 Alcalá de Henares, Madrid, Spain \\ H. Fernández and J. Solis \\ Instituto de Óptica, CSIC, Serrano 121, 28006 Madrid, Spain \\ E. Monroy \\ Equipe mixte CEA-CNRS-UJF (Nanophysique et Semiconducteurs), DRFMC/SP2M/PSC, \\ CEA-Grenoble, 17 rue des Martyrs, 38054 Grenoble Cedex 9, France
}

(Received 23 October 2006; accepted 24 January 2007; published online 26 February 2007)

\begin{abstract}
The authors report room-temperature measurements of the third order nonlinear susceptibility modulus $\left|\chi^{(3)}\right|$ of thick $(\sim 600 \mathrm{~nm})$ InN layers. Transmission measurements provide a room-temperature value for the optical band gap of the samples slightly above $1500 \mathrm{~nm}$. Third order nonlinear optical susceptibility has been measured using degenerate four wave mixing experiments at wavelengths near and above band gap. $\left|\chi^{(3)}\right|$ values of $(4.2-10) \times 10^{-10}$ esu were measured at this wavelength range. The associated relaxation time of the generated population grating at $1500 \mathrm{~nm}$ was measured. The obtained value of $4.8 \mathrm{ps}$ is consistent with a nonradiative recombination mechanism. (C) 2007 American Institute of Physics. [DOI: 10.1063/1.2709891]
\end{abstract}

Optical third order susceptibility of materials, $\chi^{(3)}$, is responsible for a variety of nonlinear phenomena, such as selffocusing, phase conjugation, and four wave mixing (FWM). ${ }^{1}$ A commonly used technique to estimate $\chi^{(3)}$ modulus is by performing forward degenerate four wave mixing (DFWM) measurements. ${ }^{2}$ The physical principle underlying FWM has been employed, for instance, to control the speed of light in GaAs quantum structures at $850 \mathrm{~nm}$ using the so-called population oscillation effect. ${ }^{3,4}$ Thus, materials with large third order nonlinear susceptibility are required for fabrication of all optically controlled devices, such as all-optical switches and wavelength converters. ${ }^{5}$

Semiconductor band-gap engineering allows the development of compact and transportable devices, with tunable operation wavelength. $\mathrm{InN}$ is particularly attractive for telecommunications, due to its room-temperature band gap around $1500-1600 \mathrm{~nm}^{6}$

In this work we have determined the third order susceptibility $\left|\chi^{(3)}\right|$ of $\mathrm{InN}$ films grown by plasma-assisted molecular-beam epitaxy (PAMBE) by using DFWM with excitation at energies around and above the band gap (1500 and $1400 \mathrm{~nm}$ ). The same technique has been used to determine the relaxation time of the excited carrier populations. ${ }^{7}$

In-face polarity InN samples were grown by PAMBE in a chamber equipped with standard effusion cells for In and Ga and a radio-frequency plasma cell to supply active nitrogen. Substrates consisted of $10-\mu \mathrm{m}$-thick nonintentionally doped (nid) GaN-on-sapphire templates. Prior to the growth of the InN layer, a 10-nm-thick nid GaN buffer layer was deposited at $720^{\circ} \mathrm{C}$. InN growth was carried out at a substrate temperature of $450{ }^{\circ} \mathrm{C}$, with a $\mathrm{N}$ flux corresponding to a growth rate of $0.3 \mathrm{ML} / \mathrm{s}$ and with an $\mathrm{In} / \mathrm{N}$ ratio of 1.2 . This high III/V ratio is required to achieve two-dimensional growth. Since the desorption rate of In is lower than the decomposition rate of $\mathrm{InN},{ }^{8}$ it is not possible to stabilize an autoregulated layer of In on the InN surface, as we demonstrated on GaN. ${ }^{9}$ Therefore, periodic growth interruptions

${ }^{a)}$ Electronic mail: naranjo@depeca.uah.es under $\mathrm{N}$ are performed to consume the In excess and prevent the accumulation of In droplets on the surface. The growth period (InN growth time/growth interruption time) of the samples and their total growth time are summarized in Table I. Taking into account the excess of In accumulated on the InN surface during growth, samples E1 and E2 are considered to be grown under slightly In-rich and N-rich conditions, respectively.

The structural quality of the samples was assessed by high-resolution $\mathrm{x}$-ray diffraction and atomic force microscopy. The full width at half maximum (FWHM) of the $\omega$ scan of the (0002) refection of the InN layers and the rms roughness measured in a surface of $5 \times 5 \mu \mathrm{m}^{2}$ are summarized in Table I.

Linear optical properties of the samples in the wavelength range of $1100-2550 \mathrm{~nm}$ were studied by roomtemperature transmission measurements at normal incidence using a Perkin-Elmer scanning spectrophotometer. Experimental results were compared with theoretical transmittance spectra generated using a three layer model (sapphire/ $\mathrm{GaN} / \mathrm{InN}$ ) (Ref. 10) to obtain values of thickness, ordinary refractive index $n_{0}(\lambda)$, and absorption coefficient $\alpha(\lambda)$ of the $\mathrm{InN}$ layer. First order Sellmeier dispersion formulas were considered for index refraction in the transparency region. ${ }^{11}$ Besides, a sigmoidal approximation was used for $\alpha(\lambda)$ for sample E1, ${ }^{12}$ while a deep level defect with $|s\rangle$-like symmetry was taken into account for sample E2. ${ }^{13}$ Transmission data of GaN substrate was analyzed considering a two layer structure (sapphire/GaN). An index of refraction of 2.23 was

TABLE I. Growth conditions and structural characterization of the samples.

\begin{tabular}{ccccc}
\hline \hline Sample & $\begin{array}{c}\text { Growth } \\
\text { sequence } \\
\text { (InN grown/N exposure) }\end{array}$ & $\begin{array}{c}\text { Total } \\
\text { growth time } \\
(\mathrm{min})\end{array}$ & $\begin{array}{c}\text { FWHM } \\
(\text { (0002) } \\
(\operatorname{arc~sec})\end{array}$ & $\begin{array}{c}\text { rms } \\
\text { roughness } \\
(\mathrm{nm})\end{array}$ \\
\hline $\mathrm{E} 1$ & $5 \mathrm{~min} / 1 \mathrm{~min}$ & 130 & 640 & 0.81 \\
$\mathrm{E} 2$ & $30 \mathrm{~s} / 6 \mathrm{~s}$ & 100 & 1260 & 2.9 \\
\hline \hline
\end{tabular}



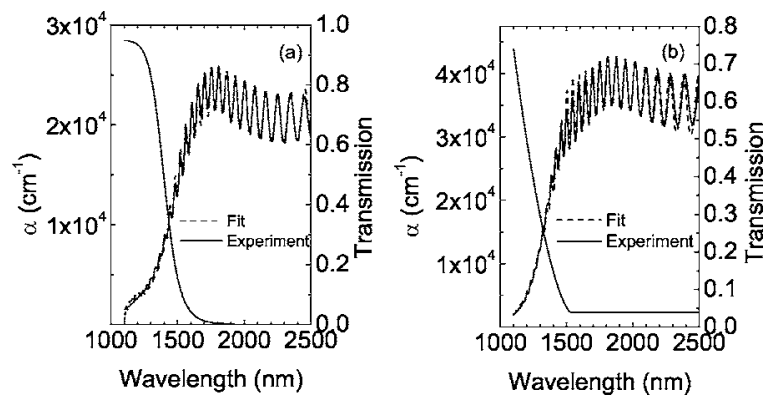

FIG. 1. Experimental and calculated room-temperature transmission spectra, and calculated absorption coefficient, for samples (a) E1 and (b) E2.

estimated for the 1400-1500 $\mathrm{nm}$ wavelength range, where the absorption was considered negligible.

Figures 1(a) and 1(b) show calculated and measured transmission data, and the absorption coefficient for samples E1 and E2, respectively. The room-temperature absorption band edge is estimated at 1550 and $1510 \mathrm{~nm}$ for samples E1 and E2, respectively. From these values we can conclude that the samples are suitable for third order optical nonlinear susceptibility measurements around $1500 \mathrm{~nm}$. Table II summarizes the linear optical estimations performed for 1400 and $1500 \mathrm{~nm}$ applied to the subsequent $\left|\chi^{(3)}\right|$ calculation.

The optical nonlinear characterization was performed by the DFWM technique in the forward configuration (boxcars) (Ref. 2) using as excitation source an optical parametric amplifier providing $100 \mathrm{fs}$ pulses, tunable in the $300-3000 \mathrm{~nm}$ interval, at a repetition rate of $1 \mathrm{kHz}$. In the DFWM measurements the conjugated beam intensity $I_{C}$ is plotted versus the pump intensity $I_{P}$ to obtain the coefficient $c$ of the relationship $I_{C}=c I_{P}^{3}$. The third order susceptibility of the samples, $\left|\chi_{s}^{(3)}\right|$, is then obtained using Eq. (1), which relates the nonlinear susceptibility of a given sample and that of a reference material with their corresponding optical parameters and conjugated signals:

$$
\left|\chi_{s}^{(3)}\right|=\left(\frac{n_{0}^{s}}{n_{0}^{r}}\right)^{2}\left(\frac{L^{r}}{L^{s}}\right)\left(\frac{c^{s}}{c^{r}}\right)^{1 / 2} \frac{\alpha L^{s} e^{\alpha L / 2}}{1-e^{-\alpha L}}\left|\chi_{r}^{(3)}\right|,
$$

where $n_{0}, L$, and $\alpha$ are the ordinary linear refractive index, the interaction length, and absorption coefficient, respectively, while superscripts $r$ and $s$ indicate parameters concerning the reference and the sample. A fused silica plate $\left[\left|\chi_{r}^{(3)}\right|=1.28 \times 10^{-14}\right.$ esu and $n_{0}=1.45$ (Ref. 2) $]$ was used as reference sample for the measurements.

In the experiment, a linear noise background caused by scattering at the sample is spatially overlapped to the conjugated beam. Considering the very small interaction lengths involved in the experiment (a few hundreds of nanometers), this background signal can be extremely detrimental for per-

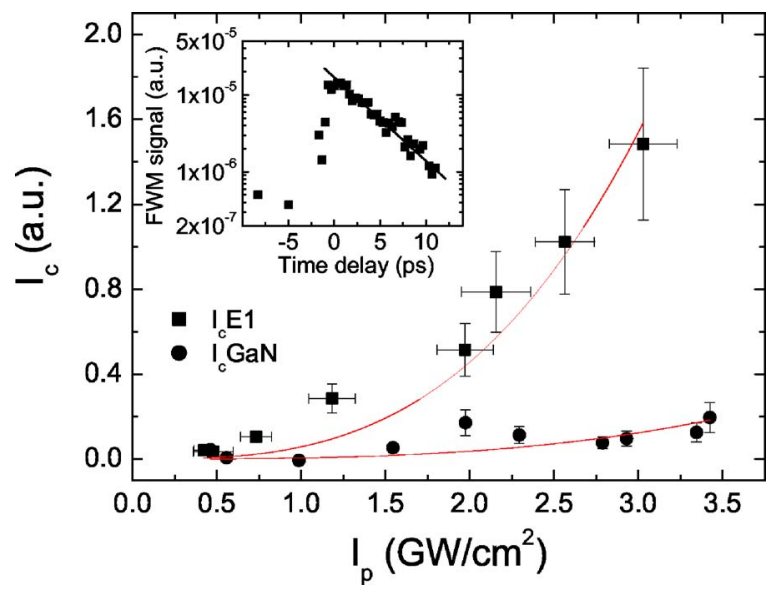

FIG. 2. $I_{s}-I_{p}$ plot for GaN template and sample E1 at $1400 \mathrm{~nm}$, showing the negligible effect of the substrate. Inset shows DFWM signal intensity obtained for sample E1 at $1500 \mathrm{~nm}$ as a function of delay time between one of the pumps and the others. The exponential decay fit used to calculate the conjugated-signal lifetime is also shown (full line).

forming a precise determination of $\left|\chi_{s}^{(3)}\right|$. Accordingly, this background was minimized by spatial filtering the conjugated beam before measuring its intensity using an InGaAs photodiode. Additionally, the remnant linear noise background was measured for different pump beam powers by introducing a large negative delay $(\sim 100 \mathrm{ps})$ between one of the pumps and the others, thus canceling the nonlinear interaction. The so-determined signal was then subtracted for each pump power from the experimentally measured conjugated-signal value. Under these conditions, the relationship between the conjugate intensity and pump beams intensity is necessarily cubic. ${ }^{2}$ Additional details about the DFWM setup can be found in Ref. 14.

The third order susceptibility of the GaN substrate was measured for 1400 and $1500 \mathrm{~nm}$ wavelengths to obtain its possible contribution to the measurements performed in the InN films. In this case, no DFWM signal was detected for pump beam intensities below $3.5 \mathrm{GW} / \mathrm{cm}^{2}$. Above this pump intensity, a value of $(4.4 \pm 0.4) \times 10^{-12}$ esu was obtained for the considered wavelengths. This result is in the order of the values obtained theoretically by Nayak et al. of 0.16 $\times 10^{-12}$ esu for zinc-blende GaN structure $^{15}$ and by Sun et al. of $0.7 \times 10^{-12}$ at $1230 \mathrm{~nm}$ experimentally. ${ }^{16}$

The InN samples were thus measured with a pump beam intensity below the above indicated value to ensure a negligible contribution from the GaN substrate. Figure 2 shows a representative plot of $I_{C}$ vs $I_{P}$ for the GaN substrate and the E1 film, showing the negligible contribution of the substrate to the film signal. Table II summarizes the measured values of $\left|\chi^{(3)}\right|$. Considering the above described procedure for

TABLE II. Summary of the results obtained from linear and nonlinear optical measurements. For sample E2, poor signal-to-noise ratio hinders reliable measurements at $1500 \mathrm{~nm}$.

\begin{tabular}{ccccccc}
\hline \hline Sample & $\begin{array}{c}\text { Thickness } \\
(\mathrm{nm})\end{array}$ & $\begin{array}{c}\text { Wavelength } \\
(\mathrm{nm})\end{array}$ & $\begin{array}{c}\alpha \\
\left(\mathrm{cm}^{-1}\right)\end{array}$ & $n$ & $\alpha L$ & $\begin{array}{c}\left|\chi^{(3)}\right| \\
(\mathrm{esu})\end{array}$ \\
\hline \multirow{2}{*}{ E1 } & 650 & 1400 & $1.4 \times 10^{4}$ & 2.95 & 0.90 & $\begin{array}{c}(1.0 \pm 0.1) \times 10^{-9} \\
\end{array}$ \\
& \multirow{2}{*}{680} & 1500 & $4.7 \times 10^{3}$ & 2.86 & 0.30 & $(5.4 \pm 0.6) \times 10^{-10}$ \\
& & 1400 & $8.7 \times 10^{3}$ & 2.78 & 0.60 & $(4.2 \pm 0.4) \times 10^{-10}$ \\
& & 1500 & $3.1 \times 10^{3}$ & 2.77 & 0.21 & $\ldots$ \\
\hline \hline
\end{tabular}


minimizing the spurious contribution of scattering to the measured conjugated signal, it is clear that the apparently poor cubic fitting obtained is simply related to the relatively low value of $\left|\chi^{(3)}\right|$ obtained and to the very small thickness of the analyzed layers (only $600 \mathrm{~nm}$ ). The value of the error bars included in the plot is related to this as well as to the fluctuations of the pump beam energy $(\sim 6 \%)$.

The close-to-resonant character of $\left|\chi^{(3)}\right|$ for $\mathrm{InN}$ in the range of wavelengths studied leads to values two orders of magnitude higher than the ones obtained for GaN. For E1, $\left|\chi^{(3)}\right|$ increases with $\alpha$ due to the close-to-resonant wavelength range. The measured values differ from theoretical predictions by Nayak et al. ${ }^{15}$ of $10^{-12}$ esu, calculated for the previously assumed $\mathrm{InN}$ band gap of $1.9 \mathrm{eV}$. E2 shows a lower value of $\left|\chi^{(3)}\right|$ when compared to sample E1 despite its higher optical density $\alpha L$ (1500 and $1400 \mathrm{~nm}$, respectively). This fact could be explained in terms of the Bursten-Moss shift of the material optical band gap observed in the linear absorption measurements (see Fig. 1). Obtained values of $\left|\chi^{(3)}\right|$ for InN are comparable to the value of semiconductors commonly used for communication applications, such as InGaAsP, with estimated $\left|\chi^{(3)}\right|$ of $4.2 \times 10^{-10}$ esu. ${ }^{17}$ Nevertheless, its application in the development of all-optical processing devices would probably require the use of InN-based structures with lower dimensionality to increase the resultant $\left|\chi^{(3)}\right|$ value. $^{18}$

We have determined the lifetime $\tau_{G}$ of the conjugated signal (associated to the dynamic grating induced at $1500 \mathrm{~nm}$ ) for sample E1 by varying the delay between one of the pumps and the others using an optical delay line. Inset of Fig. 2 shows the conjugated-signal intensity as a function of the induced delay time, showing an exponential decay. ${ }^{7}$ The lifetime estimated from this exponential decay is of $4.8 \mathrm{ps}$ at room temperature, comparable to the value of 12 ps obtained by $\mathrm{Su}$ and Chuang in a AsGa quantum dot based semiconductor optical amplifier used to obtain room-temperature slow and fast light. ${ }^{19}$ This lifetime, related to a carrier concentration grating or phase grating, is given by the equation ${ }^{7}$

$$
\frac{1}{\tau_{G}}=\frac{1}{\tau}+\frac{4 \pi^{2} D}{\Lambda^{2}}
$$

where $\tau$ is the carrier recombination time $\left(\tau_{R}\right)$ and the dephasing time $\left(\tau_{D}\right)$ for the carrier concentration and the phase grating, respectively. The second term of Eq. (2) accounts for the diffusion of the carriers, where $D$ is the diffusion coefficient and $\Lambda$ is the grating fringe spacing given by $\lambda /(2 \sin (\theta / 2)), \theta$ being the angle between pump beams. Within the experimental conditions of this work, the measured $\tau_{G}$ would lead to $D \sim 7800 \mathrm{~cm}^{2} / \mathrm{s}$, three orders of magnitude higher than typical values, ${ }^{20}$ allowing us to discard diffusion as the origin of the observed lifetime. Radiative carrier lifetime can be estimated through the expression $\left[B_{r}\left(n_{0}+\Delta n\right)\right]^{-1}$, with $B_{r}$ the bimolecular radiative recombination coefficient of $\sim 0.3 \times 10^{-10} \mathrm{~cm}^{3} \mathrm{~s}^{-1},{ }^{21} n_{0} \sim 1 \times 10^{19}$ the free carrier concentration of the samples, and $\Delta n \sim 1$ $\times 10^{19} \mathrm{~cm}^{-3}$ the photoexcited carrier concentration, leading to a value of $\sim 2 \mathrm{~ns}$, much longer than the experimentally determined one. On the other hand, dephasing time measurements on GaN lead to values of just $150 \mathrm{fs}^{22}$ Thus $\tau_{G}$ can be attributed to a nonradiative carrier relaxation mechanism in good agreement with the $16 \mathrm{ps}$ value obtained by $\mathrm{H}$. Haag et al. for $\mathrm{GaN}$ in DFWM experiments. ${ }^{23}$ Carrier recombination could take place at the defects responsible for the free carrier concentration of the samples. The origin of the measured $\chi^{(3)}$ is thus the excitation-dependent change in refractive index and absorption coefficient of the material associated with the dynamical modification of the carrier concentration caused by a near band edge excitation. Any possible cumulative thermal effects in the experiment can be neglected by considering the low laser repetition rate used $(1 \mathrm{kHz})$.

In summary, the third order optical nonlinear susceptibility of InN layers grown by PAMBE has been measured using DFWM. $\left|\chi^{(3)}\right|$ values of $(4.2-10) \times 10^{-10}$ esu were measured at wavelength ranges from 1400 to $1500 \mathrm{~nm}$. The relaxation time of the generated population grating was estimated to be $4.8 \mathrm{ps}$ at $1500 \mathrm{~nm}$, being attributed to nonradiative carrier recombination.

Thanks are due to P. Corredera and S. Fernández for valuable suggestions. Partial financial support was provided by the Spanish government Project Nos. TEC2006-09990C02-02/TCM and TEC2005-00074/MIC and by the Comunidad de Madrid, Project No. S-0505/AMB-0374.

${ }^{1}$ A. Miller, D. A. B. Miller, and S. D. Smith, Adv. Phys. 30, 697 (1981). ${ }^{2}$ R. L. Sutherland, Handbook of Nonlinear Optics (Dekker, New York, 1996).

${ }^{3}$ S.-W. Chang, S.-L. Chuang, Pei-C. Ku, C. J. Chang-Hasnain, P. Palinginis, and H. Wang, Phys. Rev. B 70, 235333 (2004).

${ }^{4}$ P. Palinginis, F. Sedgwick, S. Crankshaw, M. Moewe, and C. J. ChangHasnain, Opt. Express 13, 9909 (2005).

${ }^{5}$ D. Cotter, R. J. Manning, K. J. Blow, A. D. Ellis, A. E. Kelly, D. Nesset, I. D. Phillips, A. J. Poustie, and D. C. Rogers, Science 286, 1523 (1999). ${ }^{6}$ K. S. A. Butcher and T. L. Lansley, Superlattices Microstruct. 38, 1 (2005).

${ }^{7}$ S. Adachi, Y. Takagi, J. Takeda, and K. A. Nelson, Opt. Commun. 174, 291 (2000).

${ }^{8}$ C. S. Gallinat, G. Koblmüller, J. S. Brown, S. Bernardis, J. S. Speck, G. D. Chern, E D. Readinger, H. Shen, and M. Wraback, Appl. Phys. Lett. 89, 032109 (2006).

${ }^{9}$ E. Monroy, B. Daudin, E. Bellet-Amalric, N. Gogneau, D. Jalabert, F. Enjalbert, J. Brault, J. Barjon, and L. S. Dang, J. Appl. Phys. 93, 1550 (2003).

${ }^{10}$ M. J. Bergman, Ü. Özgür, H. C. Casey, J. F. Muth, Y. C. Chang, R. M. Kolbas, R. A. Rao, C. B Eom, and M. Schurman, Appl. Phys. Lett. 74, 3188 (1999).

${ }^{11}$ N. Antoine-Vincent, F. Natali, M. Mihailovic, A. Vasson, J. Leymarie, P. Disseix, D. Byrne, F. Semond, and J. Massies, J. Appl. Phys. 93, 5222 (2003).

${ }^{12}$ F. B. Naranjo, M. A. Sánchez-García, F. Calle, E. Calleja, B. Jenichen, and K. H. Ploog, Appl. Phys. Lett. 80, 231 (2002).

${ }^{13}$ K. S. A. Butcher, M. Wintrebert-Fouquet, P. P.-T Chen, H. Timmers, and S. K. Shrestha, Mater. Sci. Semicond. Process. 6, 351 (2003).

${ }^{14}$ R. del Csoso, J. Requejo-Isidro, J. Solis, J. Gonzalo, and C. N. Afonso, J. Appl. Phys. 95, 2755 (2004).

${ }^{15}$ S. K. Nayak, T. Sahu, S. P. Mohanty, and P. K. Misra, Semicond. Sci. Technol. 12, 544 (1997).

${ }^{16}$ C.-K. Sun, S.-W. Chu, S.-P. Tai, S. Keller, U. K. Mishra, and S. P. DenBaars, Appl. Phys. Lett. 77, 2331 (2000).

${ }^{17}$ J. P. Donnelly, H. Q. Le, A. Swanson, S. H. Groves, A. Darwish, and E. P. Ippen, IEEE Photonics Technol. Lett. 8, 623 (1981).

${ }^{18}$ K. D. Choquette, L. McCaughan, and D. K. Misemer, J. Appl. Phys. 66, 4387 (1989).

${ }^{19}$ H. Su and S. L. Chuang, Appl. Phys. Lett. 88, 061102 (2006).

${ }^{20}$ A. G. Bhuiyan, A. Hashimoto, and A. Yamamoto, J. Appl. Phys. 94, 2779 (2003).

${ }^{21}$ U. Strauss, W. W. Ruhle, H. J. Queisser, K. Nakano, and A. Ishibahi, J. Appl. Phys. 75, 8204 (1994).

${ }^{22}$ K.-H. Lin, G.-W. Chern, Y.-C. Huang, S. Keller, S. P. DenBaars, and C.-K. Sun, Appl. Phys. Lett. 83, 3087 (2003).

${ }^{23}$ H. Haag, S. Petit, P. Gilliot, R. Lévy, O. Briot, and R. L. Aulombard, Mater. Sci. Eng., B 50, 197 (1997). 